\title{
Isolated epididymal injury after blunt scrotal trauma from high velocity paintball round
}

\author{
Robert Dale, MD; Nathan A. Hoag, MD, FRCSC \\ Department of Urologic Sciences, University of British Columbia, Gordon \& Leslie Diamond Health Care Centre, Vancouver, BC
}

Cite as: Can Urol Assoc J 2015;9(5-6):E319-20. http://dx.doi.org/10.5489/cuaj.2778

Published online May 13, 2015.

\section{Abstract}

Isolated epididymal injury without associated underlying scrotal or testicular injury in the setting of blunt trauma is exceedingly rare. We present a case of an isolated epididymal injury incurred after scrotal trauma from a high velocity paintball round. Ultrasound demonstrated an enlarged, hypoechoic left epididymis with no evidence of underlying testicular injury. This case highlights the importance of obtaining imaging to evaluate for signs of testicular rupture, potentially obviating the need for surgery. It also reinforces the need for appropriate protective gear when participating in activities with potential for high velocity scrotal trauma.

\section{Case report}

A 36-year-old man presented to the emergency department with scrotal pain, swelling, and bruising to his left hemiscrotum. Three days prior, he had been shot in the scrotum with a paintball gun while attending a bachelor party. His medical history was unremarkable other than previous bilateral inguinal hernia repair. Physical examination demonstrated left scrotal swelling and tenderness. A palpable, moderate-sized hematoma was appreciated within the left hemiscrotum.

Scrotal ultrasound demonstrated symmetrical and homogenous testes, with right and left testes measuring $5.0 \times 2.5 \times 2.7 \mathrm{~cm}$ and $2.9 \times 2.9 \times 4.6 \mathrm{~cm}$, respectively. The left epididymis appeared enlarged, thickened, and heterogeneous in echotexture with an associated small hematocele (Fig. 1). These findings were consistent with an isolated epididymal hematoma with no evidence of testicular injury.

Our patient was managed expectantly with analgesics, ice, and scrotal support. In follow-up 1 week later, his pain had resolved and the swelling had decreased. On physical examination, the size of his scrotal hematoma had significantly decreased.

\section{Discussion}

Blunt scrotal trauma is most often caused by athletic injury $(50 \%)$, motor vehicle collision $(9 \%-17 \%)$, or assault, and comprises less than $1 \%$ of trauma-related injuries. ${ }^{1,2}$ Possible injuries include testis rupture, avulsion, torsion, and hematoma. However, isolated epididymal injury without accompanying scrotal or testicular injury is exceptionally rare. ${ }^{3}$

Clinical evaluation of the painful, swollen scrotum can be difficult, especially when trying to delineate between pathology requiring surgical intervention versus conservative management. Before widespread use of ultrasound as a diagnostic adjunct, surgical exploration was the standard of care. Early surgical exploration leads to high testicular salvage rates along with reduced rates of delayed orchiectomy. ${ }^{4}$ However, with high-resolution colour Doppler ultrasound, serious scrotal injuries requiring surgical repair, including testicular rupture and avulsion, can be ruled out with sensitivity approaching $100 \% .{ }^{5}$ Appropriate selection of patients for conservative management can avoid unnecessary surgery and its associated complications. In patients with high-risk mechanisms and with unclear imaging findings, surgical exploration remains prudent.

This case highlights the importance of genitourinary protection during sporting activities. Most blunt scrotal trauma is sporting-related and occurs in males between the ages of 3 and 45 year old. ${ }^{6}$ Congeni and colleagues surveyed 755 male high school and collegiate athletes on genitourinary injury awareness. Up to $47 \%$ of high school and collegiate athletes reported not wearing genitourinary protective gear during sporting activity and only one-third reported that they would seek medical attention for testicular pain and swelling. ${ }^{7}$ There is an obvious need for education among young athletes and parents on appropriate use of protective gear, as well as the importance of seeking medical attention after scrotal trauma. Sports with inherent risk of high velocity genitourinary trauma, such as paintball, present substantial risk for scrotal injury, and the use of protective gear, such as a "cup," should be advocated by urologists. 


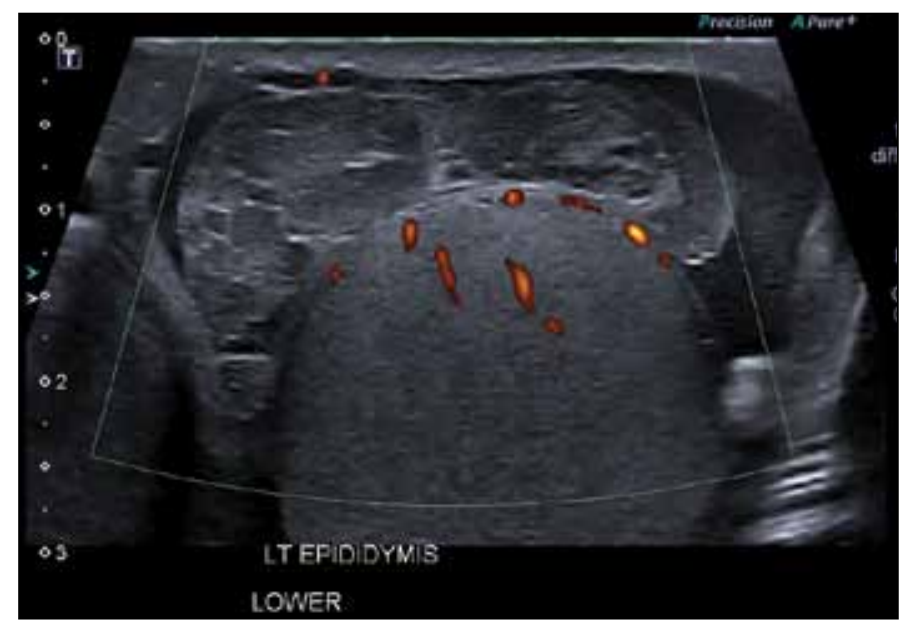

Fig. 1. Colour Doppler ultrasound of the left hemiscrotum demonstrating a large, heterogeneous, hypoechoic epididymis without signs of underlying testicular injury.

Isolated epididymal injuries in the context of blunt scrotal trauma are uncommon and usually associated with other testicular injury. ${ }^{5}$ It should be noted that testicular rupture secondary to paintball injury has been reported, and this diagnosis must be excluded before considering conservative management. ${ }^{8}$ Gordon and colleagues ${ }^{9}$ describe traumatic epididymitis as hyperemia of an enlarged epididymis on Doppler ultrasound. An enlarged, hypoechoic epididymis can also be associated with hydrocele, hematoma, and underlying epididymal injury. ${ }^{10}$ While these findings are non-specific on their own, with appropriate clinical history of trauma and absence of associated testicular injury, it can be used to support the diagnosis of an isolated epididymal injury, which is usually managed conservatively. While it is not known with certainty what future effect this type of injury may have on sperm transport and eventual fertility, avoiding scrotal exploration in these cases may minimize the potential damage to the epididymis itself, and patients should be counselled accordingly.

\section{Conclusion}

We present a 36-year-old male who was shot in the scrotum by a paintball gun and sustained an isolated epididy- mal hematoma without associated injury to the testicle. Diagnosis was confirmed using colour Doppler ultrasound demonstrating enlargement of the left epididymis with surrounding hematoma. The patient was managed conservatively with analgesics, ice, and scrotal support. Ultrasound of the scrotum following trauma plays a crucial role in evaluating the need for surgical exploration versus conservative management. Though surgical exploration is warranted if the diagnosis remains uncertain, it is important to optimally delineate the extent of injury to avoid any unnecessary surgery, and its possible associated complications.

Competing interests: The authors declare no competing financial or personal interests.

This paper has been peer-reviewed.

\section{References}

1. Deurdulian C, Mittelstaedt C, Chong WK, et al. US of acute scrotal trauma: Optimal technique, imaging findings, and management. Radiographics 2007;27:357-69. http://dx.doi.org/10.1148/rg.272065117

2. Munter DW, Faleski EJ. Blunt scrotal trauma: Emergency department evaluation and management. Am J Emerg Med 1989;7:227-34. http://dx.doi.org/10.1016/0735-6757(89)90143-5

3. Dogra V, Gottlieb R, Oka M, et al. Sonography of the scrotum. Radiology 2003;227:18-36. http:// dx.doi.org/10.1148/radiol.2271001744

4. Cass AS, Luxenberg M. Value of early operation in blunt testicular contusion with hematocele. J Urol 1988;139:746-7.

5. Guichard G, El Ammari J, Del Coro C, et al. Accuracy of ultrasonography in diagnosis of testicular rupture after blunt scrotal trauma. Urology 2008;71:52-6. http://dx.doi.org/10.1016/j.urology.2007.09.014

6. Bagga $\mathrm{HS}$, Fisher PB, Tasian $\mathrm{GE}$, et al. Sports-related genitourinary injuries presenting to United States emergency departments. Urology 2015;85:239-45. http://dx.doi.org/10.1016/i.urology.2014.07.075

7. Congeni J, Miller SF, Bennett CL. Awareness of genital health in young male athletes. Clin I Sport Med 2005;15:22-6. http://dx.doi.org/10.1097/00042752-200501000-00005

8. Joudi FN, Lux MM, Sandlow Jl. Testicular rupture secondary to paint ball injury. J Urol 2004;171:797. http://dx.doi.org/10.1097/01.ju.0000106504.26268.e9

9. Gordon LM, Stein SM, Ralls PW. Traumatic epididymitis: Evaluation with color Doppler sonography. Am J Roentgenol 1996;166:1323-5. http://dx.doi.org/10.2214/air.166.6.8633441

10. Ragheb D, Higgins JL. Ultrasonography of the scrotum: Technique, anatomy, and pathologic entities. J Ultrasound Med 2002;21:171-85.

Correspondence: Dr. Robert Dale, UBC Department of Urologic Sciences, Gordon \& Leslie Diamond Health Care Centre, Level 6, 2775 Laurel St., Vancouver, BC V5Z 1M9; robert.t.dale@gmail.com 